\title{
EDUCADORES E EDUCADORAS SOCIAIS E OS SERVIÇOS DE CONVIVENCIA E FORTALECIMENTO DE VÍNCULOS EM IVAIPORÃ-PR: AÇÃO EDUCATIVA COM CRIANÇAS E ADOLESCENTES COM DIREITOS VIOLADOS
}

\author{
Lucas Henrique da Luzi $₫ 0000-0002-3278-401 X$ \\ Universidade Estadual de Maringá - UEM \\ Paula Marçal Nataliii $₫ 0000-0003-4641-0083$ \\ Universidade Estadual de Maringá - UEM \\ Verônica Regina Müller ${ }^{\mathrm{iii}} @ 0000-0002-0438-3518$ \\ Universidade Estadual de Maringá - UEM
}

RESUMO: As relações educativas estabelecidas por educadores sociais no âmbito do Serviço de Convivência e Fortalecimento de Vínculos se constituem como o tema desta pesquisa. A Educação Social no Brasil está em processo de constituição, não tendo até o presente momento um processo formativo formal definido voltado aos profissionais, entretanto constatamos um grande número de instituições e projetos atuando neste âmbito. Este trabalho pretende investigar o desenvolvimento da ação educativa dos educadores sociais em três instituições de Serviço de Convivência e Fortalecimento de Vínculos e como se constitui o entendimento e desenvolvimento do trabalho dos educadores sociais sobre direitos violados de crianças e adolescentes. A pesquisa é de caráter qualitativo, do tipo exploratório. Para a construção dos dados utilizamos como metodologia a observação das ações educacionais das instituições e entrevistas semiestruturadas com oito educadores sociais, a análise dos dados foi feita a partir da análise de conteúdo de Bardin (1977). Os resultados do estudo nos mostraram fragilidade no âmbito formativo dos profissionais envolvidos na ação educativa, que contrasta com o tempo em que estas ações são desenvolvidas e a quantidade de crianças e adolescentes atendidas no município. Apontou-se que é urgente uma maior atenção e dedicação às bases formativas dos profissionais da Educação Social que, podem resultar em uma prática educativa mais efetiva e que atinja de forma mais contundente os objetivos do atendimento educativo de crianças e adolescentes com direitos violados.

PALAVRAS-CHAVE: Educação social. Formação e Atuação. Infância e adolescência.

\section{SOCIAL EDUCATORS AND THE INTERACTIONAL AND STRENGTHENING OF BONS PROGRAM OF IVAIPOR ̃̃-PR: EDUCATION PRACTICE WITH CHILDREN AND ADOLESCENTS WITH VIOLATED RIGHTS}

ABSTRACT: The topic of this research was the educational relations established by social educators at an Interactional and Strengthening of Bonds Program. Social Education in Brazil is a work in progress, currently lacking a formal training aimed at professionals, despite the fact of a great number of institutions and projects operating in the said field. Our purpose is to study the development of social educator's educational practices at three institutions of Interactional and Strengthening of Bonds Program, and social educators build and develop their work regarding children and adolescents with violated rights. This is qualitative research, exploratory in nature. Data gathering methodology utilized observation of the institution's educational practices, semistructured interviews with eight social educators. The data analysis made use of content analysis by Bardin (1977). Results conveyed deficiency concerning professional training for those involved in educational practices, in contrast with how long these practices have being developed and how many children and adolescents utilize the city's program. We urgently point at a more attentive dedication to training de Social Educators, resulting in a more effective educational practice and better accomplishing the goals of educational support to children and adolescents with violated rights.

KEYWORDS: Social Education. Training and Practice. Childhood and Adolescence. 


\section{Apresentação}

No decorrer da história da educação constatamos muitas mudanças e transformações nas configurações do ensinar e nestes processos observamos sempre a figura do educador e a luta e persistência exigidas do ato de educar. Dentre as áreas da educação os papéis dos seus profissionais variam de acordo com as legislações, conteúdos e objetivos educacionais referentes ao tempo em que ocorrem. Partindo de uma perspectiva mais ampla do que a educação mais comumente desenvolvida em nosso contexto, a Educação escolar, trazemos nesta pesquisa um debate sobre a Educação Social, que pode também ocorrer em escolas, porém não se limita a ela.

Em nosso entendimento a Educação Social firma um comprometimento direto com a educação para os direitos humanos, é uma educação situada no tempo e que visa o acesso das diferentes pessoas aos bens culturais disponíveis na sociedade. Entendemos a Educação Social como:

Una práctica educativa que opera sobre lo que lo social define como problema. Es decir, trabaja em territorios de frontera entre lo que las lógicas ecónomicas y sociales van definiendo em términos de inclusión / exclusión social, com elfin de paliar o, em su caso, transformar los efectos segrativos em los sujetos. La educación social atiende a la producción de efectos de inclusión cultural, social y económica, al dotar a los sujetos de los recursos pertinentes para resolver los desafios del momento histórico (NUÑEZ, 1999, p. 26).

Deste modo, a Educação Social se desvela e se firma de várias formas, tornando evidente a necessidade de o educador sempre reanalisar sua práxis dentro do seu contexto de atuação. Esta destreza pode redimensionar sua compreensão de mundo e possibilitar observar tal mundo também com os olhos do educando, beneficiando sua prática pedagógica e também a si mesmo (PAIVA, 2011).

Partindo desta compreensão da área o objetivo do artigo em tela é investigar o desenvolvimento das ações educativas de educadores sociais em três instituições do Serviço de Convivência e Fortalecimento de Vínculos-SCFV e como se constitui o entendimento e desenvolvimento do trabalho dos educadores sociais sobre direitos violados de crianças e adolescentes no município de Ivaiporã-PR.

O SCFV está no Brasil relacionada as ações das secretarias de Assistência Social e faz parte da proteção básica, essa forma de atendimento educativo desenvolve ações com muitas crianças e adolescentes, na maioria das vezes com direitos violados, tendo como mediador o 
educador social. Os SCFV são definidos na Tipificação Nacional de Serviços Socioassistenciais como:

[...] constituição de espaço de convivência, formação para a participação e cidadania, desenvolvimento do protagonismo e da autonomia das crianças e adolescentes, a partir dos interesses, demandas e potencialidades dessa faixa etária. As intervenções devem ser pautadas em experiências lúdicas, culturais e esportivas como formas de expressão, interação, aprendizagem, sociabilidade e proteção social. Inclui crianças e adolescentes com deficiência, retirados do trabalho infantil ou submetidos a outras violações, cujas atividades contribuem para re-significar vivências de isolamento e de violação de direitos, bem como propiciar experiências favorecedoras do desenvolvimento de sociabilidades e na prevenção de situações de risco social (BRASIL, 2009, p. 12).

O SCFV faz parte da política de proteção básica, e pode ser ofertado no Centro de Referência da Assistência Social-CRAS ou nos centros de convivência (BRASIL, 2015). A proteção básica [...] visa prevenir situações de risco e vulnerabilidades, investindo no desenvolvimento de potencialidades, no fortalecimento de vínculos familiares/comunitários, e oferecendo a possibilidade de aquisições coletivas e individuais (BRASIL, 2010, p. 29).

Neste estudo analisamos as ações educativas em três SCFV na cidade de Ivaiporã-PR que trabalham com crianças e adolescentes:

\begin{tabular}{|c|l|}
\hline INSTITUIÇÃO & \multicolumn{1}{|c|}{ OBJETIVO } \\
\hline $\begin{array}{c}\text { PROJETO } \\
\text { RENASCER }\end{array}$ & $\begin{array}{l}\text { O projeto busca garantir a integridade e autonomia das } \\
\text { crianças e adolescentes, uma vez que as oficinas } \\
\text { buscam incluir nossos jovens adolescentes na } \\
\text { sociedade contemporânea (DEPARTAMENTO } \\
\text { MUNICIPAL DE ASSISTENCIA SOCIAL, 2017). }\end{array}$ \\
\hline CASA DE & $\begin{array}{l}\text { Possibilitar o desenvolvimento integral da criança no } \\
\text { aspecto físico, psicológico, intelectual, } \\
\text { VIVÊNCIA } \\
\text { estar, o crescimento e pleno desenvolvimento da } \\
\text { criança (PREFEITURA } \\
\text { IVAIPORÂ, 2016). }\end{array}$ \\
\hline CENTRO DA & $\begin{array}{l}\text { Produzir e acessar bens culturais e artísticos, participar } \\
\text { de atividades esportivas e tecnológicas, desenvolver e } \\
\text { participar de ações que favoreçam a formação pessoal, } \\
\text { profissional e política, espaços estes a serem mantidos } \\
\text { pelos Municípios beneficiados, tendo como público } \\
\text { prioritário jovens de 12 a 18 anos de idade em situação } \\
\text { de vulnerabilidades e direitos violados (CEDCA-PR, } \\
\text { 2009). }\end{array}$ \\
\hline
\end{tabular}


Este estudo faz parte do projeto de pesquisa "Educação Social e Ludicidade: Configurações e Trajetórias na Infância e adolescência" da Universidade Estadual de Maringá, que envolve estudos sobre educação social em 4 municípios do Paraná. A pesquisa tem aprovação do Comitê Permanente de Ética em Pesquisa com Seres Humanos - COPEP, da Universidade Estadual de Maringá (CAAE62838116.0.0000.0104).

Para realização desta pesquisa utilizamos como método, a observação participante afim de conhecermos e observarmos o cotidiano de cada SCFV e a entrevista semiestruturada, que pode ser entendida como:

[...] aquela que parte de certos questionamentos básicos, apoiados em teorias e hipóteses, que interessam à pesquisa, e que, em seguida, oferecem amplo campo de interrogativas, fruto de novas hipóteses que vão surgindo à medida que se recebem as respostas do informante (TRIVIÑOS, 1987, p. 146).

Uma forma de entrevista que mescla perguntas fechadas e abertas, na qual o educador entrevistado poderia ter a liberdade de dissertar sobre o tema sem se prender a pergunta inicial formulada (MINAYO; DESLANDES; GOMES, 2012).

Visando o desenvolvimento do estudo, no primeiro momento estabelecemos contato com as instituições, apresentamos nossa proposta de pesquisa e obtivemos permissão para realizar a pesquisa, posteriormente conversamos com os educadores que também concordaram em participar totalizando o número de oito entrevistados. Todo o conteúdo das observações e entrevistas realizadas foram transcritas e estão no texto em itálico e as falas do pesquisador em meio a estes dados estão destacadas entre colchetes. Nas transcrições das entrevistas semiestruturadas atribuímos nomes fictícios para os educadores sociais entrevistados para preservar suas identidades.

Para tratarmos o material coletado por meio da entrevista semiestruturada, utilizamos a análise de conteúdo de Bardin (1977) utilizando um:

[...] conjunto de técnicas de analise das comunicações visando obter, por procedimentos, sistemáticos e objectivos de descrição do conteúdo das mensagens, indicadores (quantitativos ou não) que permitam a inferência de conhecimentos relativos as condições de produção/recepção (variáveis inferidas) destas mensagens (BARDIN, 1977, p. 42).

Por fim, no decorrer do artigo analisamos as seguintes categorias encontradas nos aspectos formativos, contratuais dos educadores, função e papel, formação, tempo para 
planejamento, contratação, entrada na área e também questões estruturais dos SCFV com intuito de explicitar como se categoriza o trabalho de educadores e educadoras dentro destas instituições no município de Ivaiporã-PR.

\section{O Educador e Educadora Social no Serviço de Convivência e Fortalecimentos de Vínculos: Formação e atuação}

O ECA reestruturou o debate em torno dos direitos humanos e o modo de pensar a criança e adolescente. $\mathrm{O}$ estatuto possibilitou de mais políticas públicas que também se respaldam pautado no artigo $227^{\circ}$ da Constituição Federal, que afirma:

É dever da família, da sociedade e do Estado assegurar à criança, ao adolescente e ao jovem, com absoluta prioridade, o direito à vida, à saúde, à alimentação, à educação, ao lazer, à profissionalização, à cultura, à dignidade, ao respeito, à liberdade e à convivência familiar e comunitária, além de colocá-los a salvo de toda forma de negligência, discriminação, exploração, violência, crueldade e opressão (BRASIL, 1988, p. 93-94).

Também foi a partir da promulgação do ECA que aumentaram as instituições e projetos da área da Educação Social trazendo junto com ele a figura do educador social de forma mais contundente. Natali (2016) nos evidencia que os educadores passaram a ter grande enfoque dos seus trabalhos no ECA, visto que eles trabalham muitas vezes com crianças com seus direitos violados e em vulnerabilidade social. Porém no contexto analisado na pesquisa notamos a ausência da discussão da garantia de direitos na fala dos educadores sociais apresentando um distanciamento com as situações das crianças e adolescentes que frequentam os SCFV estudados. Apenas um único educador citou o ECA e apenas uma vez em suas falas:

Temos o ECA aí também que muitas vezes a gente vê ser rasgado, pisado em algumas situações literalmente, quando a gente vê alguns relatos de algumas crianças aqui, daí a gente para e pensa quem tem a mínima base do conhecimento do ECA e fala poxa vida (Educador José)

O fato de termos encontrado em entrevistas com educadores sociais um único relato sobre o ECA se faz preocupante devido o significado e à importância desta legislação para o contexto do trabalho com crianças e adolescentes com direitos violados em que os profissionais estão inseridos. Quando se trabalha com tal categoria geracional o educador entra em contato direto com crianças e adolescentes com seus direitos violados, sendo assim, 
potencializá-los politicamente e ensiná-los é muito importante e necessário para que o educando entenda seus direitos e deveres e se reconheça como sujeito de direito. Este conhecimento é imprescindível para a atuação na Educação Social.

No que se refere aos objetivos do trabalho com educação para os direitos humanos de crianças os educadores nos falaram sobre suas funções e podemos notar que em alguns relatos os educadores falaram sobre a prevenção, e também do processo de intervenção para conhecêlas e conhecer sobre suas situações, por fim um educador nos relata que os SCFV trabalham com crianças que tiveram ou apresentam seus direitos violados:

[...] a função principal do educador aqui, todos aqui dentro, não só eu, é voltado a prevenção, é notar que ele tá entrando... Dá pra ver pelas atitudes dele, a nossa função aqui é notar né, avaliação pré educativa [...] a intenção é essa né, notar e agir perante a ele para que não entre nessa área de criminalidade, de uso de drogas e com isso melhorar ele né (Educador Maurício).

[...] o primeiro ponto é nós tentarmos extrair o máximo possível dessa criança de informação para depois futuramente para passar para nossa coordenadora que leva a quem compete dentro do departamento de assistência social, muitas vezes psicólogo, muitas vezes acionando o conselho tutelar, mas daí isso não é de início porque muitas das crianças, criança é assim a gente vê que é um pouquinho complicado, porque muitas vezes eles não se abrem com qualquer um [...] (Educador José).

Para ocorrer tais intervenções e se estabeleça o processo educativo se faz necessário a comunicação entre os serviços assegurando o trabalho articulado entre as instituições, já que o SCFV também compõe a proteção básica organizando-se em grupos (BRASIL, 2015). É importante destacar a presença de "oficinas" nos SCFV, de esporte, lazer, arte e cultura que funcionam como "meio" para propiciar a convivência e os vínculos entre participantes e educadores (BRASIL, 2015). Neste eixo que o educador social deve atuar e desenvolver seu trabalho, segundo a tipificação do serviço.

Para realização destas "oficinas" é instituída a figura do instrutor ou educador social, que para exercer tal função necessita ao menos ter como escolaridade o ensino médio concluído (BRASIL, 2015) o que entendemos como incompatível com a complexidade de saberes necessário para se atuar na Educação Social.

De acordo com as orientações governamentais o papel dos educadores sociais dentro dos SCFV, seria: 
Organizar, facilitar oficinas e desenvolver atividades coletivas nas unidades e/ou na comunidade; acompanhar, orientar e monitorar os usuários na execução das atividades; apoiar na organização de eventos artísticos, lúdicos e culturais nas unidades e/ou na comunidade; participar das reuniões de equipe para o planejamento das atividades, avaliação de processos, fluxos de trabalho e resultado; Acompanhar e registrar a assiduidade dos usuários por meio de instrumentais específicos, como listas de frequência, atas, sistemas eletrônicos próprios, etc. (BRASIL, 2015, p. 28).

Porém os papéis nos quais os educadores sociais entendem que tem nas instituições estudadas são variados, como papéis que dão enfoque no cuidar comparando até mesmo com o papel da família:

Na verdade, a gente tem um papel importante, somos como pais para eles né, a gente tem que ensinar, corrigir, e prevenir que eles busquem coisas erradas né, é bem parecido com o lado familiar mesmo (Educador Mauricio).

Também encontramos uma educadora que focaliza o educar:

Eu acho que é um apoio, claro que a gente participa do processo de formação da educação da criança né, porque a já gente não tá só no cuidar, mas sim no educar, todo meio que a criança está presente [...] (Educadora Silvia).

Educadores que focaram seu entendimento na prevenção de problemas que a criança possa vir a ter em suas falas:

A função, é de intervir em algum problema que ela tenha, ter um olhar mais crítico em relação ao meio social, um olhar mais minucioso em relação a criança saber o que que ela, o que passa, sei lá, na casa dela ou tentar entender um pouco a criança (Educadora Julia).

[...] o Professor aqui hoje tem que ser muito mediador, acaba sendo não só um professor da educação física, o educador social atua muito como psicólogos, como pai, como estruturador das crianças que aqui frequentam né (Educador Gabriel).

E também encontramos um educador que falou sobre a potencialização dos educandos:

A função da educação social é essa, é potencializar a vida da criança dando aquele direito que ela tem e que nunca deveria ter perdido, ensinando quais 
são os direitos que elas têm, direitos e deveres, a eu acho que é isso (Educador Arthur).

As funções e papéis apresentados pelos educadores divergem muito e ainda em algumas falas constatamos caráter assistencialista, protecionista e sentimos falta em algumas falas de ações pedagógicas voltadas ao desenvolvimento humano dos educandos (MÜLLER et al, 2010). Portanto, as falas caracterizam-se como um distanciamento do próprio entendimento de seu papel como profissional, apontamos que um princípio inegociável para uma atuação efetiva e de qualidade é que se compreenda e se tenha claro o objetivo de seu trabalho como educador social, o qual compreendemos, conforme as definiçõoes de Bauli e Müller (2020, p. 388-389):

Mediar e formar pessoas, famílias, comunidade, apresentando conteúdos culturais, políticos e cívicos com o intuito de instrumentalizar os sujeitos para a sua emancipação social [...]Ir até as diferentes populações, ser um personagem presente e de referência na comunidade, informar sobre as ofertas culturais, Acompanha as pessoas aos serviços de interesse, ensinar ou acompanhar para a cultura artística, esportiva, recreativa, política, profissional, filosófica, histórica, dos direitos e deveres, das ciências humanas e sociais; éticos

Para este grande leque de atribuições atreladas aos educadores sociais consideramos imprescindível tempo de planejamento, encontro entre os educadores, debates e discussões que proporcionem a reflexão sobre as ações educativas. Entretanto, nas instituições estudadas, não identificamos horários para planejamento, nem para organização e estruturação de atividades, este momento não foi relatado por nenhum dos educadores:

Não tenho hora atividade (Educador Mauricio).

\section{[...] eu planejo em casa só (Educadora Julia).}

Nós tivemos um planejamento no começo do trabalho [...] Não, não tem hora atividade, o planejamento a gente não é necessariamente seguir a rigor, a gente tem uma liberdade pra trabalhar até legal (Educador Gabriel).

Fator que tem grande influência na atuação dos educadores, pois sem tempo de planejamento eles acabam sobrecarregados com suas rotinas e não apresentando tempo para organizar suas atividades e nem refletir sobre elas, como descreve o Educador Arthur: 
[...] é muito corrido, para falar verdade é pouco tempo até para você trabalhar, então você tem que preparar algo assim que você sabe que vai dar conta naquele curto período que você tem para trabalhar.

Outro fato relatado pelo mesmo educador se faz a rotina rígida seguida pelos educadores que muitas vezes os impossibilita de realizarem atividades e implicam em suas atuações:

[...] se vamos supor, nove horas eu quiser sair, não tem como eu sair da sala porque já vai ter outra turma lá fora, eu tenho um horário pra seguir (Educador Arthur).

Sobre a formação profissional, encontramos educadores já formados atuando e também estudantes de algum curso de graduação, como relatam os educadores sobre como e o que necessitaram para trabalhar nos cargos que estão atualmente:

[...] agora eu estou atuando neste momento na área da assistência social como professor de educação física a partir de um concurso público há dois anos atrás (Educador Mauricio).

[...] eu ainda fazia faculdade quando eu vim para cá [...] no início eu entrei como estagiária (Educadora Maria).

[...] eu precisava ser acadêmico ou estar fazendo uma pós né, aí como eu sou acadêmico de educação física, então eu pude entrar nessa vaga aí que tinha aqui na casa de vivência (Educador Eduardo).

[...] eu fiz o concurso em 2014 e me chamaram agora em 2017 [...] a princípio o concurso só exigia educação física, aí depois eles passaram a exigir o bacharel também ao invés só da licenciatura (Educador Gabriel).

Como podemos perceber, alguns SCFV de Ivaiporã-PR exigiram como requisito mínimo estar cursando algum curso de alguma graduação, porém encontramos também um SCFV que exigiu no concurso a formação de licenciatura em Educação Física e depois passaram a exigir também o bacharel em Educação Física como pré-requisito para atuação.

[...] no meu contrato, é o processo seletivo, não tô como efetivo da prefeitura, digamos assim, como eu posso dizer, um concursado, pra concurso a prefeitura exige sim ensino superior, agora pra processo seletivo, aí é nível médio, até por questão que eu não vou entrar em valores, mas por questão de remuneração por exemplo, ou pelo concurso, se fosse pra eu estar atuando pelo concurso, digamos que o meu salário seria o dobro do que eu recebo hoje [...] (Educador José). 
Bauli e Müller (2020) ao analisarem 24 Editais de Seleção Pública, identificaram que $72 \%$ dos documentos identificados elencaram como requisito mínimo de trabalho a formação em ensino médio e $28 \%$ em nível superior de ensino. Isto se refletiu diretamente nos salários, onde o educador social de nível médio apresentou média salarial de $\mathrm{R} \$ 1.222,29$ e o educador contratado em nível superior R \$ 2.486,95 como média. Já em relação a jornada de trabalho, os autores apontam que "o Educador Social de nível médio tem jornada de 40 horas em 100\% das amostras. Se o Educador tem formação superior, 14,3\% das vagas já lhe oportunizam jornada de 30 horas semanais" (p. 116).

Em suma, o educador contratado com nível mínimo médio tem menor salário e maior jornada de trabalho que podem refletir diretamente na sua atuação, ainda mais quando somamos a precariedade formativa para exercer as atribuições para o cargo. Também encontramos nos SCFV analisados diferenças metodológicas e pedagógicas nos modos de atuação dos educadores e das próprias instituições:

Com várias atividades acontecendo ao mesmo tempo as crianças e os adolescentes transitavam entre os locais do SCFV, apresentando liberdade para escolherem o que mais lhes agradavam (Diário de campo, 24/08, Centro da juventude)

Nesta instituição ocorre uma divisão de turmas por idades semelhantes, onde cada sala apresenta um educador que aplicam atividades para os educandos, algo semelhante as instituições escolares, porém um atividades, objetivos e métodos diferentes (Diário de campo, 06/09/2017, Projeto Renascer)

Neste SCFV as crianças e adolescentes com idades aproximadas são divididos por turmas e durante o dia realizam atividades no pátio ou permanecem com os professores de sala realizando atividades, semelhante ao método escolar, porém não há disciplinas (Diário de campo, 23/08/2017, Casa de vivência).

Como podemos perceber duas instituições trabalhavam com o sistema de turmas e outra instituição apontava um método diferente, enquanto uma delas não havia ensalamento e os educandos podiam escolher qual oficina realizar, as outras duas continham educadores de sala e cada turma tinha horários específicos nas oficinas ofertadas. Sistema parecido com o descrito por Mager et al (2011) que nos explica metodologia do Projeto Brincadeiras, nos dizendo que os educadores se posicionam em lugares distintos e as crianças apresentam livre arbítrio para escolherem suas brincadeiras e opinarem nas regras, sugerirem, fazerem parte do processo da educação que ali acontece. Com uma forma de trabalhar mais semelhante à 
instituição descrita por última e as duas primeiras de forma mais semelhante a organização escolar.

Além das diferentes metodologias, encontramos discrepantes realidades em cada SCFV visitados:

A estrutura deste SCFV aparentou ser muito antiga, com estruturas de alvenaria e cerâmica, salas em situações ruins, aparentemente muitos locais improvisados, materiais sendo reutilizados por diversas vezes $e$ apresentando aparência desgastada, uma sala de alvenaria sem terminar de ser construída e abandonada (Diário de campo, 23/08/ 2017, Casa de Vivência)

O centro da juventude é composto por uma grande estrutura com várias salas decoradas, quadra, piscina, sala de dança, sala de teatro, biblioteca, mesas de jogo expostas no pátio para todos jogarem, uma quantidade enorme de materiais, sala de informática e uma pista de skate (Diário de campo, 24/08/2017, Centro da Juventude)

A estrutura do Projeto Renascer compõe uma grande quadra, parquinho, pátio com mesas de tênis de mesa, sala de informática e música, um mini salão de beleza, pátio para as refeições, equipamentos novos, salas de aula e também uma sala de dança (Diário de campo, 06/09, Projeto Renascer)

Sendo assim, podemos ver uma grande disparidade dentre os SCFV de Ivaiporã, enquanto dois deles apresentam estruturas em ótimo estado, uma grande gama de materiais, a instituição Casa de vivência apresenta uma situação bem diferente, com estruturas antigas e necessitando de reformas, e também pouco lugar para as crianças brincarem, como descrito abaixo:

Durante a brincadeira uma outra educadora surge gritando e falando para que eles não brincassem ali na grama, mas o educador que estava ali com eles balançou os ombros e disse que iria usar ali para brincar sim, pois não havia outro lugar (Diário de campo, 15/09/ 2017, Casa de Vivência)

O educador inconformado com as condições relatou que havia pouco espaço e que havia uma quadra, porém ela estava em reforma. A escassez de materiais também nos foi dito pelo educador que relatou ter apenas uma bola para eles utilizarem (Diário de campo). Em questão de infraestrutura observamos essa séria divergência que ocasiona em situações como a descrita acima, na qual as crianças perdem seus espaços de brincarem e também a qualidade e quantidade de seus materiais oferecidos pelos SCFV. 
Outro ponto que observamos se faz na grande variedade de formas com que eles tiveram o primeiro contato com a Educação Social, desta forma os educadores nos descreveram como entraram na área da Educação Social:

Bom, meu primeiro contato com o departamento de assistência social, fui contratado para dar estágio a quatro anos atrás, aí eu estagiei, aprendi a trabalhar com isso [...] (Educador Mauricio).

A, eu vim para cá por indicação mesmo [...] tinha uma amiga minha que trabalhava aqui, eu tinha acabado de me mudar para cá, então eu recebi o convite, de na verdade de dar aula de dança no início, aí eu vim para cá, foi assim (Educadora Maria).

[...] ]eu comecei a fazer faculdade a noite, da educação física, então eu tava procurando serviço na cidade de Ivaiporã inteira, seja em qualquer área, na minha área ou em qualquer área, daí minha mãe conhecia o $C$. [coordenador] e falou que tava precisando de alguém, no caso, da minha área, daí na hora eu vim pra cá e já conversei com o C. [Coordenador] $e$ consegui entrar nessa área aí da educação [...] (Educador Eduardo)

[...] eu entrei porque fui chamada para trabalhar lá no [R. SCFV] [...] eu só perguntei para $S$. [Coordenadora] se estava precisando de estagiário lá, e ela falou que precisava, e como eu já dei estágio lá e ela gostou (Educadora Julia).

[...] a educação social para mim entrou realmente de paraquedas (Educador Arthur)

[...] surgiu a possibilidade através de um amigo meu, ele comentou que o projeto aqui estaria precisando de educadores né [...] eu deixei o currículo aqui com eles né, e foi a partir disso aí eles já me chamaram mesmo, no início daquele mesmo ano já me chamaram para iniciar [...] (Educador José).

Como podemos observar os educadores sociais que trabalham com a linguagem de jogos e brincadeiras dentro dos SCFV, apresentam uma grande heterogeneidade quando comparadas as suas histórias que os levaram a adentrar nesta área de atuação, alguns literalmente caíram de "paraquedas" e outros entraram por meio de concursos e processos seletivos.

Segundo Müller et al (2010), no Brasil os educadores que trabalham na Educação Social sofrem com o desconhecimento e a dificuldade de identificá-los, em suas diversas formações, fato que acarreta na falta de identidade profissional e contribui para fragilidade na área, fragilidade esta encontrada por nós, como visto nas falas acima, a falta de identidade profissional, desconhecimento da função do educador pelos próprios educadores aparecendo 
diversos papéis diferentes para a mesma função profissional, como o cuidar, prevenir, potencialização, recreação.

Quando observamos os SCFV relacionando com a falta de claridade em suas funções e o modo no qual os educadores adentraram a área da Educação Social, também conseguimos encontrar pontos importantes que somam a estes e devem ser revistos, em nosso ponto de vista como por exemplo, a divisão de salas entre gênero, as salas são divididas entre meninas e meninos como relata o educador a seguir:

[...] aqui vocês podem ver que a partir de dos maiores eles separam uma turma mais com meninos e mais com meninas, é uma coisa que eu particularmente eu não concordo, não vejo que tenha que ser dessa forma, mas até muitas vezes [...] (Educador José).

[...] porque umas tem habilidade um pouco a mais de artesanato, então as meninas se identificam mais, então elas acabam ficando mais com aquela professora, então foi um coisa que foi feito no decorrer dos anos aí, no começo não era assim e acabou sendo feito depois, eu tento muitas das vezes pra tirar um pouco essa, essa questão de divisão de meninos e meninas, acabar tirando as turmas juntas pra eles ter convicto né, porque eu acho que eles não, o convívio não tem que ser podado nem, nem nada do tipo, não é uma coisa que a gente tenta, mas tem que evitar no máximo alguns conflitos ou algumas situações [...] (Educador José).

Porém a divisão de turmas por gênero e a diferença das relações com as funções e papéis das crianças dentro do SCFV se tornam ações que contribuem para a divisão sexista da sociedade, e tal dicotomização tende a colocar a mulher em papéis e funções menos favorecidas ou valorizadas pelos padrões héteronormativos presentes em nossa sociedade, desta forma nos posicionamos contra tal modo de ensalamento (FERREIRA; GOULART, 2008), (JESUS; DEVIDE, 2007). ]

\section{Considerações}

Neste artigo analisamos as relações estabelecidas dos educadores aos SCFV, a questão dos direitos violados e o distanciamento apresentado a questão da violação de direitos. Os SCFV analisados apresentaram diferenças estruturais dentre eles, alguns com grandes investimentos e outros sobrevivendo com poucos equipamentos e salas em más condições.

Enquanto em dois SCFV havia grandes quantidades de materiais e boas instalações, o terceiro funcionava em um local antigo e continha para atuação dos educadores pouquíssimos materiais. 
Sendo assim, observamos realidades diferentes que também abrangiam as questões metodológicas e organizacionais utilizadas por cada SCFV, enquanto dois deles optaram por turmas, ensalamento e uma divisão mais rígida dos horários, o terceiro dá autonomia às crianças e adolescentes para escolher de qual atividade participar, de poder sair das atividades, pois várias aconteciam ao mesmo tempo e ali as crianças apresentavam a livre escolha de transitar dentre elas.

Destes SCFV, um deles apresentou também uma rotina demasiadamente densa, na qual o educador enfrenta dificuldades para atuar, pois "é muito corrido, pra falar verdade é pouco tempo até pra você trabalhar". Observamos também que nenhum dos educadores entrevistados apresentaram horário para planejamento de suas atividades, fato que influencia diretamente as ações educativas desenvolvidas.

Encontramos também um SCFV que apresentava turmas separadas por gênero, ou com predominância de um, separando as turmas entre meninos e meninas, fator que pode contribuir para dicotomização sexista da sociedade, e os priva da convivência como um todo e entre todos.

Os SCFV apresentam diversas diferenças em seus funcionamentos e muitos pontos nos quais devem melhorar, como a oferta de horário para planejamento, por fim nas salas divididas por gênero, e também por parte dos órgãos gestores a divisão justa das rendas destinadas a cada um deles, mas também observamos educadores que mesmo sem formação apresentaram aspectos importantíssimos da ação educativa da Educação Social, educadores que se posicionam diante de injustiças e pedem melhorias, e locais que possibilitarem grande promoção cultural dos educandos.

Já a respeito dos educadores sociais, estes entraram de diversos modos na área da Educação Social, como descreve o educador Arthur "a educação social pra mim entrou realmente de paraquedas", esta entrada se refere a multiplicidade de modos nos quais ocorreram os encontros com a área, muitas vezes por indicação de um parente ou amigo, por concurso, por necessidade, sem conhecer esta área da educação, dentre outros modos.

Além de caírem de paraquedas nos SCFV, os educadores também mostraram divergências em suas funções e papéis dentro das instituições e encontramos um único educador que citou o ECA e enfatizou o trabalho com os direitos violados, apresentando um ponto preocupante diante dos objetivos da Educação Social e da condição e situações das crianças e adolescentes que frequentam os SCFV.

De forma geral, a relação dos SCFV com os educadores se fizeram precárias, sem hora atividade, formação, dificuldade na organização da rotina que pode afetar a atuação dos 
educadores e com uma grande confusão na identificação dos papéis e funções que lhes cabem, sendo visto diversas afirmações diferentes para uma mesma função a se realizar no seu âmbito de atuação profissional, o que demonstra fragilidade na atuação dos educadores e suas relações estabelecidas com as instituições.

\section{REFERÊNCIAS}

BARDIN, L. Análise de conteúdo. Lisboa: Edições 70, 1977.

BRASIL, Ministério do Desenvolvimento Social e Combate à Fome. Caderno de Orientações: Serviço de Proteção e Atendimento Integral à Família e Serviço de Convivência e Fortalecimento de Vínculos Articulação necessária na Proteção Social Básica, Brasília, 2015.

BRASIL, Ministério do Desenvolvimento Social e Combate à Fome. Orientações Técnicas Sobre o Serviço de Convivência e Fortalecimento de Vínculos para Crianças e Adolescentes de 6 A 15 Anos. Brasília, 2010

BRASIL, Ministério do Desenvolvimento Social e Combate à Fome. Tipificação Nacional de Serviços Socioassistenciais. Brasília, 2009.

BRASIL. Código de Menores, Lei Federal 6.697, de 10 de outubro de 1979. Disponível em: http://www.planalto.gov.br/ccivil_03/leis/1970-1979/L6697.htm Acesso em: 02/jul./2017.

BRASIL. Constituição Federal de 1988. Brasília, 1988. Disponível em: http://www.planalto.gov.br/ccivil_03/constituicao/constituicaocompilado.htm Acesso em: 15/jun./2017.

CEDCA-PR. Deliberação n ${ }^{\circ} 04$ em 31 de março de 2009. Programa Centros da Juventude. SECJ, 2009. Departamento Municipal de Assistência Social. Projeto Renascer: planejamento, ações, eventos. Ivaiporã, 2017.

ESPÍNDULA, D. H. P.; SANTOS, M. F. S. Representações sobre a adolescência a partir da ótica dos educadores sociais de adolescentes em conflito com a lei. Revista Psicologia em Estudo, Maringá, v. 9, n. 3, p. 357-367, 2004.

FERREIRA, C. M. R; GOULART, S. R. A educação física e a co-educação: igualdade ou diferença? Revista Brasileira de Ciências do Esporte, Florianópolis, SC, v. 23, n. 2, Jul. 2008. Disponível em: http://revista.cbce.org.br/index.php/RBCE/article/view/269 Acesso em: 01/Nov./2017.

LEITE, C. C. Da doutrina da situação irregular à doutrina da proteção integral: aspectos históricos e mudanças paradigmáticas. In: Juizado da Infância e Juventude / [publicado por] Tribunal de Justiça do Estado do Rio Grande do Sul, Corregedoria-Geral da Justiça. N. 1 (nov. 2003). Porto Alegre: Departamento de Artes Gráficas do TJRS, 2003.

MAGER, M.et al. Práticas com crianças, adolescentes e jovens: pensamentos decantados. Maringá: EDUEM, 2011.

MINAYO, M. C. S; DESLANDES, S. F; GOMES, R. (Org.). Pesquisa Social: Teoria, método e criatividade. 31. ed. Petrópolis/RJ: Vozes, 2012.

MÜLLER, V. R. et al. A formação do profissional da Educação Social: espectros da realidade. XVIII Seminário Internacional de Formação de Professores para o MERCOSUL/CONE SUL. 2010, Florianópolis. Anais eletrônicos... Florianópolis: 2010. 
Disponível em: $\quad$ http://seminarioformprof.ufsc.br/files/2010/12/M\%C3\%9CLLERVer\%C3\%B4nica-Regina3.pdf Acesso em: 10/jul./2017.

NATALI, P. M. Formação Profissional na Educação Social: Subsídios a Partir de Experiências de Educadores Sociais Latino Americanos. 243f. Tese (Doutorado em Educação) - Universidade Estadual de Maringá. Maringá, 2016.

NUÑEZ, V. Pedagogía Social: Cartas para Navegar em el Nuevo Milenio. Satillana: Buenos Aires, 1999.

OLIVEIRA, W. F. de. Educação Social de Rua: as bases políticas e pedagógicas para uma Educação Popular. Porto Alegre: Artmed, 2004.

PAIVA, J. S. de. Compreendendo as Vivencias e Experiências, Produzidas na Educação Social de Rua: Desvelamentos Pertinentes ao Educador Social de Rua. 2011. 245 f. Tese (Doutorado em Educação) - Universidade Federal do Espírito Santo, Vitória, 2011.

PREFEITURA MUNICIPAL DE IVAIPORÃ. DEPARTAMENTO DE ASSISTÊNCIA SOCIAL. Projeto Casa de vivência/Casa do Adolescente: relatório de atividades 2016. Ivaiporã, 2016.

RIZZINI, I; RIZZINI, I. A institucionalização de crianças no Brasil: percurso histórico e desafios do presente/Irene, Rio de Janeiro: Ed. PUC-Rio; São Paulo: Loyola, 2004.

TRIVINÕS, A. N. S. Introdução a pesquisa em ciências sociais: a pesquisa qualitativa em educação. São Paulo: Atlas, 1987.

VANNUCHI, P. T.; OLIVEIRA, C. S. de. Direitos humanos de crianças e adolescentes: 20 anos do Estatuto. Brasília: Secretaria de Direitos Humanos, 2010.

Graduado em Educação Física pela Universidade Estadual de Maringá (UEM). Email: lucasnba147@gmail.com

ii Doutora em Educação pela Universidade Estadual de Maringá (UEM), docente da mesma instituição, Campus Regional do Vale do Ivaí e coordenadora do Programa Multidisciplinar de Estudo, Pesquisa e Defesa da Criança e do Adolescente-PCA/UEM. Email: paulamnatali@gmail.com

iii Doutora e pós-doutora em História da Educação Social Contemporânea (Universidade de Barcelona), docente Universidade Estadual de Maringá (Mestrado e Doutorado em Educação) e membro da coordenadora do PCA (Programa Multidisciplinar de Estudos, Pesquisa e Defesa da Criança e do Adolescente). E-mail: vrmuller@uem.br 